\title{
Estimation of probable maximum precipitation for tropical catchment
}

\author{
Saad Sammen ${ }^{1}$, Thamer Mohamed ${ }^{1}$, Abd Alhalim Ghazali ${ }^{1}$, Lariyah Sideq ${ }^{2}$ and Azlan Abdul Aziz ${ }^{1}$ \\ ${ }^{1}$ Department of Civil Engineering, Faculty of Engineering, University Putra Malaysia. Serdang, Selangor, Malaysia \\ ${ }^{2}$ Department of Civil engineering, College of Engineering, University Tenaga Nasional, Kajang, Selangor, Malaysia
}

\begin{abstract}
Probable Maximum Precipitation (PMP) is the maximum precipitation depth for specific region or station within a certain time. The main purpose of PMP estimation is calculate the Probable Maximum Flood (PMF). The PMF is considered necessary for design and manage the hydraulic structures. PMP can be estimate using two methods, either using a physical method or by using statistical method. In this study, statistical approach was used to estimate the PMP for Temengor catchment in Perak state, Malaysia. Extreme value type-1 distribution (EV1) is adopted to estimate the extreme rainfall and Hershfeid method was used to estimate PMP value. Also, intensity duration curve (IDC) was derived for 1, 2 and 3 days storm duration with return period 5, 10, 50, 100, 500 years. The results showed that the values of PMP for 1000 return period are $222.361 \mathrm{~mm}, 311.847 \mathrm{~mm}$ and $348.307 \mathrm{~mm}$ for 1,2 and 3 days respectively.
\end{abstract}

\section{Introduction}

The PMP has been given the definition as being the greatest depth of precipitation for a particular time period which is meteorologically possible over a specified area or given station (World Meteorological Organization (WMO), 1986). Two techniques are commonly applied for calculating the PMP value, physical method and statistical method. In physical method the PMP for various time periods are calculated by maximize and transposition of actual storm events. In order to produce a PMP value that will satisfy for the lack of a sufficient storm database, storm transposition and envelopment methods are incorporated. For around the last 2 decades, the PMP has been estimated many times for dam in Malaysia using methods of maximization and transposition (NAHRIM, 2008; Desa et al., 2007).

Statistical approach is the second common technique that used for PMP estimation. A statistical method is applied for the estimation of the PMP rainfall at a given area or location which is calculated from the distribution of the frequency fitted to the maximum rainfall records annually. The annual maximum rainfall data are usually used as a key variable in problems related to hydraulic structures design. The philosophy on which this is based is that, if the structure which has been designed is able to attitude the maximum value in one year, it will also be able to attitude other values. The statistical technique is more useful when meteorological data, other than an abundance of rainfall data, are unavailable, such as wind speed and dew point temperatures.
Another kind of statistical technique used to estimate PMP values for areas which are small was developed by Hershfield $(1961,1965)$. This technique was based on an equation for general frequency presented by Chow (1951). This technique requires a series of maximum annual daily rainfall measurements at a particular observation point as the input data. Hershfield's statistical method has been employed, extensively, in the estimation of PMP for areas which have a long duration of recorded rainfall data. Therefore, Hershfield's method was considered desirable for undertaking in this study to estimating the PMP for 1 day and 3-day durations in the Temengor Catchment stations as their data for daily rainfall is available for long durations.

\section{Study area and data collection}

The study area for this work was at the Temengor catchment station covering a total area size of $3506 \mathrm{~km}^{2}$. The catchment area's elevation ranges from $206 \mathrm{~m}$ to $2156 \mathrm{~m}$. Lake Temengor covers about a $150 \mathrm{~km}^{2}$ area of the catchment which is otherwise forested. The location map for the catchment area of Temengor is shown in Figure 1.

One of the basic requirements for estimating the PMP is long period rainfall data. Rainfall is a vital element in the hydrological cycle; as such, rainfall needs to be quantified when various water resource projects are being planned and designed. Generally, to quantify rainfall, intensity-duration-frequency (IDF) curves are used (Chow et al., 1988). For this study, seven rainfall stations were used. These stations were located upstream 
of the Temengor dam as shown in Figure 2. The properties of the rainfall stations are presented in Table 1.

\section{Theory of hershfield method}

Chow's (1951) method for analyzing the frequency of rainfall was adapted by Hershfield when developing his technique to estimate the PMP. For a hydrological analysis, Chow (1951) suggested applying the following formula for frequency distributions.

$$
\mathrm{x}_{\mathrm{PMP}}=\mathrm{x}_{\mathrm{n}}{ }^{-}+\mathrm{K}_{\mathrm{m}} \cdot \sigma_{\mathrm{n}}
$$

When estimating the PMP, the factor $K_{m}$ can be calculated by applying the formula:

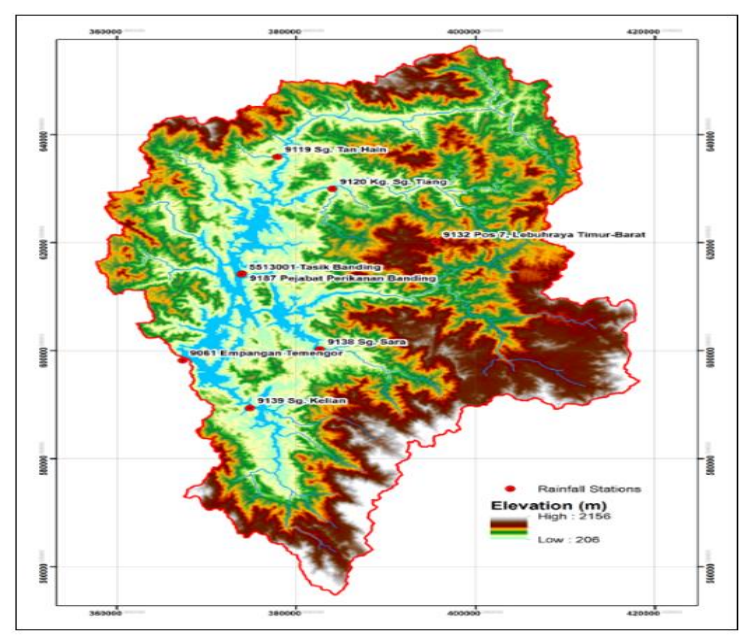

Fig. 1. Map of Temengor catchment

Table 1. Details of rainfall stations at Temengor catchment

\begin{tabular}{|c|c|c|c|c|}
\hline \multirow{2}{*}{ St. No. } & \multirow{2}{*}{ St. Name } & \multicolumn{2}{|c|}{ Coordinate } & \multirow{2}{*}{$\begin{array}{l}\text { St. Height } \\
\text { above S.L } \\
\text { MSE (m) }\end{array}$} \\
\hline & & Lat. & Long. & \\
\hline 9138 & Sg. Sara & $052532 \mathrm{~N}$ & $1012556 \mathrm{E}$ & 270 \\
\hline 9132 & Lebuhraya Timur & $053620 \mathrm{~N}$ & $1013254 \mathrm{E}$ & 1042 \\
\hline 9120 & Kg. Sungai Tiang & $054138 \mathrm{~N}$ & $1012638 \mathrm{E}$ & 260 \\
\hline 9187 & Pejabat Perikanan & $053306 \mathrm{~N}$ & $1012113 \mathrm{E}$ & 285 \\
\hline 9139 & Sg. Kelian & $051937 \mathrm{~N}$ & $1012143 \mathrm{E}$ & 259 \\
\hline 9061 & Empangan & $052423 \mathrm{~N}$ & $1011738 \mathrm{E}$ & 185 \\
\hline 9119 & Sg. Tan Hain & $054451 \mathrm{~N}$ & $1012318 \mathrm{E}$ & 258 \\
\hline
\end{tabular}

$$
\mathrm{K}_{\mathrm{m}}=\left(\mathrm{X}_{1}^{-}-\mathrm{X}_{\mathrm{n}-1}{ }^{-}\right) / \sigma_{\mathrm{n}-1}
$$

Where

$X_{\text {PMP: }}$ PMP value for specific station

$\mathrm{X}_{\mathrm{n}}^{-}$: Average of maximum annual rainfall $\sigma_{\mathrm{n}}:$ Standard deviation maximum annual rainfall

$\mathrm{K}_{\mathrm{m}}$ : Coefficient related to Frequency

$\mathrm{X}_{1}^{-}$: Maximum value of maximum annual rainfall

$\mathrm{X}_{\mathrm{n}-1}{ }^{-}$: Mean of annual maxima, excluding highest

$\sigma_{\mathrm{n}-1}$ : Standard deviation of annual maxima, excluding highest

A survey conducted on more than 2600 stations worldwide calculated the factor $\mathrm{K}_{\mathrm{m}}$, above, as ranging from the highest value of 14.5 down to a value under 3 . In Hershfield's work, he adopted the highest value and rounded it up to 15 in order to estimate the PMP.

$$
\mathrm{X}_{\mathrm{PMP}}=\mathrm{x}_{\mathrm{n}}^{-}+15 \sigma_{\mathrm{n}}
$$

Research works undertaken in the USA, Canada, and India have shown that in areas where the annual rainfall is very heavy, the value of $\mathrm{K}_{\mathrm{m}}=15$ tends to result in values of the PMP which are determined to be too large when using other techniques. In addition, in areas where the annual rainfall is low, the values are too small. As a result, rather than using the highest value of $\mathrm{K}_{\mathrm{m}}=15$, used worldwide, a more appropriate $K_{m}$ value was considered to be one based on stations in Malaysia, which would result in a more reliable estimation of the PMP.

The estimation of the PMP for various locations is not dependent on the single highest value of $\mathrm{K}_{\mathrm{m}}$ in that area as was shown by Hershfield (1965). Rather, he found that, the $\mathrm{K}_{\mathrm{m}}$ that had been derived, empirically, was different, inversely, from the mean of the series, and directly with the duration of the rainfall. That is to say, when the mean of the series $\left(\mathrm{X}_{\mathrm{n}}\right)$ rose in magnitude, the $\mathrm{K}_{\mathrm{m}}$ value tended to become lower. Therefore, each location will have its own $\mathrm{K}_{\mathrm{m}}$ value which is dependent on the magnitude of the location's $\mathrm{X}_{\mathrm{n}}$. Following that, Hershfield (1965) employed the envelope $K_{m}$ curve to obtain $\mathrm{K}_{\mathrm{m}}$ values for a variety of $\mathrm{X}_{\mathrm{n}}$ values. Therefore, it was concluded that, if an appropriate envelope curve could be developed based upon the locations in the study area, it would provide realistic estimates of the PMP for various time periods of rainfall. Consequently, appropriate envelope $\mathrm{K}_{\mathrm{m}}$ curves representing the relation between $\mathrm{K}_{\mathrm{m}}$ and the mean annual maximum rainfall were found for various time periods of rainfall. However, the natural characteristics of rainfall was realized, leading to $K_{m}$ versus $X_{n}$ curves being created for a variety of time periods for the location.

Recently National Hydraulic Research Institute Malaysia (NAHRIM) has conducted a PMP (Technical Research Publication No.1 - Derivation of Probable Maximum Precipitation for Design Flood in Malaysia, 2008) study covering the whole Malaysia where they have established standard method of estimating PMP by both statistical and hydro-meteorological methods. In statistical method, envelop curves for frequency factor $\left(\mathrm{K}_{\mathrm{m}}\right)$ of different duration storm events were developed with respect to their corresponding mean annual maximum precipitation values (Figure 3 ). Second degree polynomial equations were then derived for each of the envelop curves which are then used to determine the $\mathrm{K}_{\mathrm{m}}$ 
value of any particular location of a catchment or station where the mean of annual maximum rainfall is available. These curves have been found useful for the determination of $\mathrm{K}_{\mathrm{m}}$ values for any location in Peninsular Malaysia and hence been used for the Temengor catchment PMP calculation.

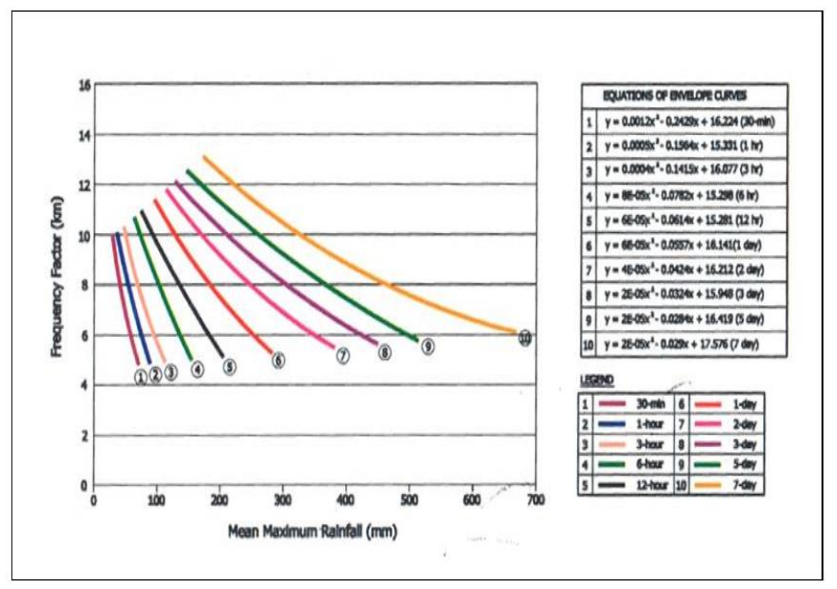

Fig. 3. $\mathrm{K}_{\mathrm{m}}$ Envelope curves for different durations in west Malaysia (NAHRIM, 2008)

\section{Methodology}

The most widely used statistical method for estimating the PMP is by Hershfield $(1961,1965)$ which has become one of the standard methods suggested by the World Meteorological Organisation (WMO, 1986) for estimating the PMP at any location. The flow chart for PMP establishment is shown in Figure 4. Therefore, it is considered desirable to carry out a study on the estimation of PMP for 1, 2 and 3 days.

Rainfall analysis was carried out to use Gumble Extreme Value (GEV). The values were determined for 5, 10, 20, 50, 100, 1000 and 10000 year ARI. Frequency analysis was carried out for 1 day and 3 days rainfall storm duration for the Temengor Reservoir. According to Gumble theory of extreme events, the probability of occurrence of an event equal to or larger than a value $\mathrm{X}_{\mathrm{o}}$ is

$$
\mathrm{P}\left(\mathrm{x} \geq \mathrm{x}_{\mathrm{o}}\right)=1-\mathrm{e}^{-\left(\mathrm{e}^{\wedge}-\mathrm{y}\right)}
$$

Where y is dimensionless variable given by

$$
\begin{aligned}
& \mathrm{y}=\alpha(\mathrm{x}-\mathrm{a}) \\
& \mathrm{a}=\mathrm{x}-0.45005 \sigma_{\mathrm{x}} \\
& \alpha=1.2825 / \sigma_{\mathrm{x}}
\end{aligned}
$$

Where: $\mathrm{x}$ is the mean value of the recorded rainfall and

$\sigma_{X}$ is the standard deviation of the recorded rainfall. For the required $P$, eq. (4) can be rearrange to

$$
\mathrm{y}_{\mathrm{P}}=-\ln (-\ln (1-\mathrm{P}))
$$

If $\mathrm{P}$ is replace by return period $\left(T_{P}=1 / P\right), y_{T}$ is given by

$$
\mathrm{y}_{\mathrm{T}}=-\left(\ln \cdot \ln \left(\mathrm{T}_{\mathrm{P}} / \mathrm{T}_{\mathrm{P}}-1\right)\right.
$$

Now rearrange eq. (4), the value of $\mathrm{x}$ with the return period $\left(T_{P}\right)$ is given by

$$
\mathrm{X}_{\mathrm{T}=\mathrm{x}+\mathrm{K}} \cdot \sigma_{\mathrm{x}}
$$

Where: $\mathrm{x}_{\mathrm{T}}$ is the estimated event magnitude and $\mathrm{K}$ is given by

$$
\mathrm{K}=\left(\mathrm{y}_{\mathrm{T}}-0.577\right) / 1.2825
$$

Note that eqn (10) is of the same form as the general equation of hydrologic frequency analysis.

\section{Results and discussion}

The rainfall intensity is commonly required for planning and designing of various water resource projects. Many sets of relationships have been developed and used in several parts of the world. Rainfall intensity were estimate for storm duration of 1day and eight different return periods of $5,10,20,50,100,500$ and 1000 years. Frequency analysis techniques are used to estimate the rainfall intensity, for different return periods from rainfall data. Distribution analysis of rainfall frequency is based on Type I extreme value (Gumbel) distributions. Areal precipitation of the study area was obtained by adopting Thiessen polygon method using Geographical Information System (GIS) technique as shown in Figure 4. Also from Thiessen Polygons, The mean area weights or proportion of rainfall that a station contributes to

\begin{tabular}{|c|c|c|}
\hline $\begin{array}{c}\text { Rainfall Station } \\
\text { Name }\end{array}$ & $\begin{array}{r}\text { Area } \\
\left(\mathrm{Km}^{2}\right)\end{array}$ & $\begin{array}{c}\text { Respective } \\
\text { Weight }\end{array}$ \\
\hline 9138 Sg. Sara & 571.417 & 0.166 \\
\hline $\begin{array}{c}\text { 9132, Lebuhraya } \\
\text { Timur-Barat }\end{array}$ & 797.926 & 0.232 \\
\hline 9120 Kg. Sg. Tiang & 431.013 & 0.125 \\
\hline $\begin{array}{c}9187 \text { Pejabat Perikanan } \\
\text { Banding }\end{array}$ & 430.361 & 0.125 \\
\hline 9139 Sg. Kelian & 600.925 & 0.175 \\
\hline $\begin{array}{l}9061 \text { Empangan } \\
\text { Temengor }\end{array}$ & 112.374 & 0.033 \\
\hline \multirow[t]{2}{*}{9119 Sg. Tan Hain } & 490.445 & 0.143 \\
\hline & $\begin{array}{l}\sum \text { Area }= \\
3434.461\end{array}$ & $\begin{array}{c}\sum \text { Respective } \\
\text { Weight }=1\end{array}$ \\
\hline
\end{tabular}
catchment were determined as shown in Table 2. By using this frequency distribution function, the maximum rainfall intensity for durations of 5, 10, 20, 50, 100, 500 and 1000 years return periods, have been determined as shown in Table 3. Intensity duration curve for 1, 2 and 3 days and different return period was shown in Figure 5.

Table 2. Weight of rainfall stations to compute main rainfall 


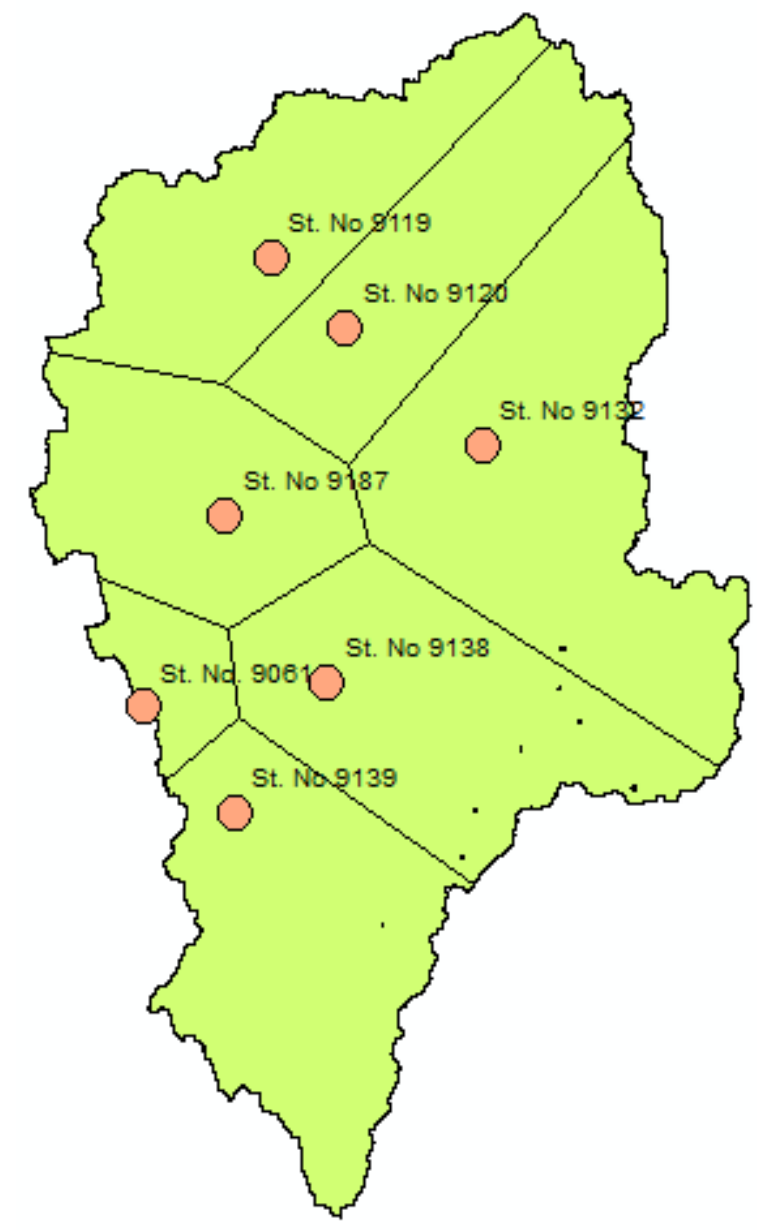

Fig. 4. Thiessen polygons derived for the study area

Table 3. Rainfall depth (PMP) for different return period

\begin{tabular}{|c|c|c|c|}
\hline \multirow{2}{*}{ Return Period (years) } & \multicolumn{3}{|c|}{ Rainfall Intensity } \\
\cline { 2 - 4 } & $\mathbf{1}$ day & $\mathbf{2}$ days & 3 days \\
\hline $\mathbf{5}$ & 99.084 & 137.736 & 158.69 \\
\hline $\mathbf{1 0}$ & 116.192 & 161.899 & 185.00 \\
\hline $\mathbf{5 0}$ & 153.845 & 215.079 & 242.92 \\
\hline $\mathbf{1 0 0}$ & 169.763 & 237.56 & 267.40 \\
\hline $\mathbf{5 0 0}$ & 206.547 & 289.512 & 323.98 \\
\hline $\mathbf{1 0 0 0}$ & 222.361 & 311.847 & 348.30 \\
\hline
\end{tabular}

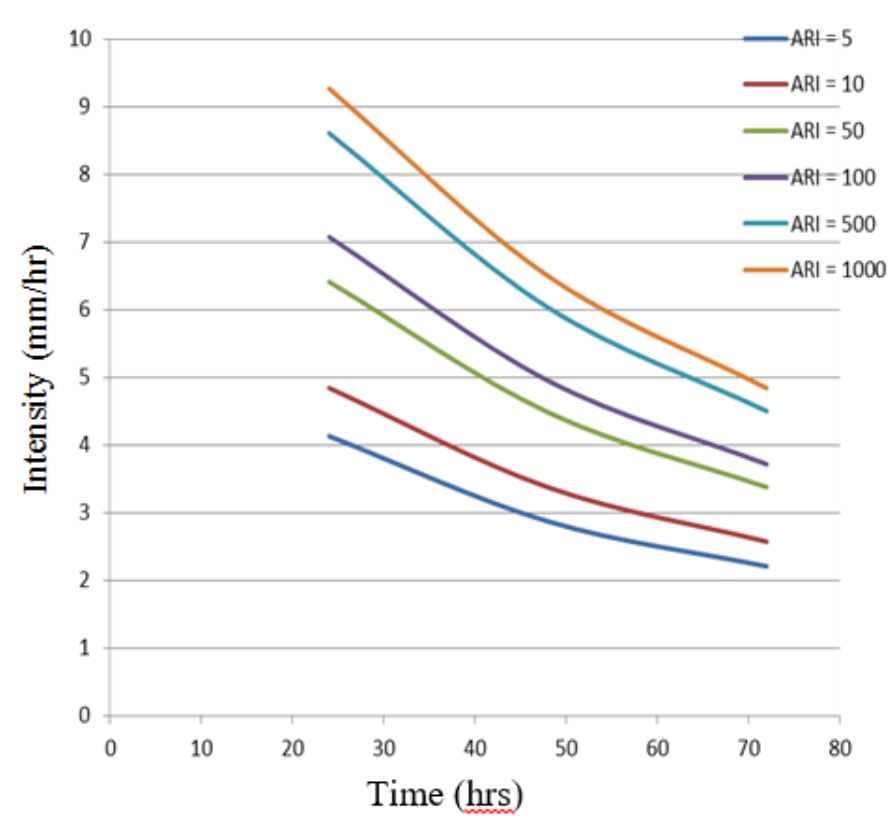

Fig. 5. Intensity Duration Curve

\section{References}

1. World Meteorological Organisation, 1986, Operational Hydrology Report No.1, WMO No. 332, 96-108, (Second Edition).

2. National Hydraulic Research Institute of Malaysia (NAHRIM) (2008). Nahrim Technical Research Publication No.1 (TRP 1).

3. Desa, M. N.; Rekhecha, P. R., 2007, Atmos, Res, 84, 84 - 90 .

4. Hershfield, D. M., 1961: J. Hyd. Div., Am. Soc. of Civil Eng., 87, Hy5, 99-116.

5. Hershfield, D.M., 1965: J. Am. Water Works Assoc., 57, 965-972.

6. Chow, V. T., 1951: Trans. Am. Geophys. Union, 32, 231-237.

7. Chow V.T.,D.R. Maidment and L.W. Mays (1988). "Applied Hydrology". McGraw-Hill. 


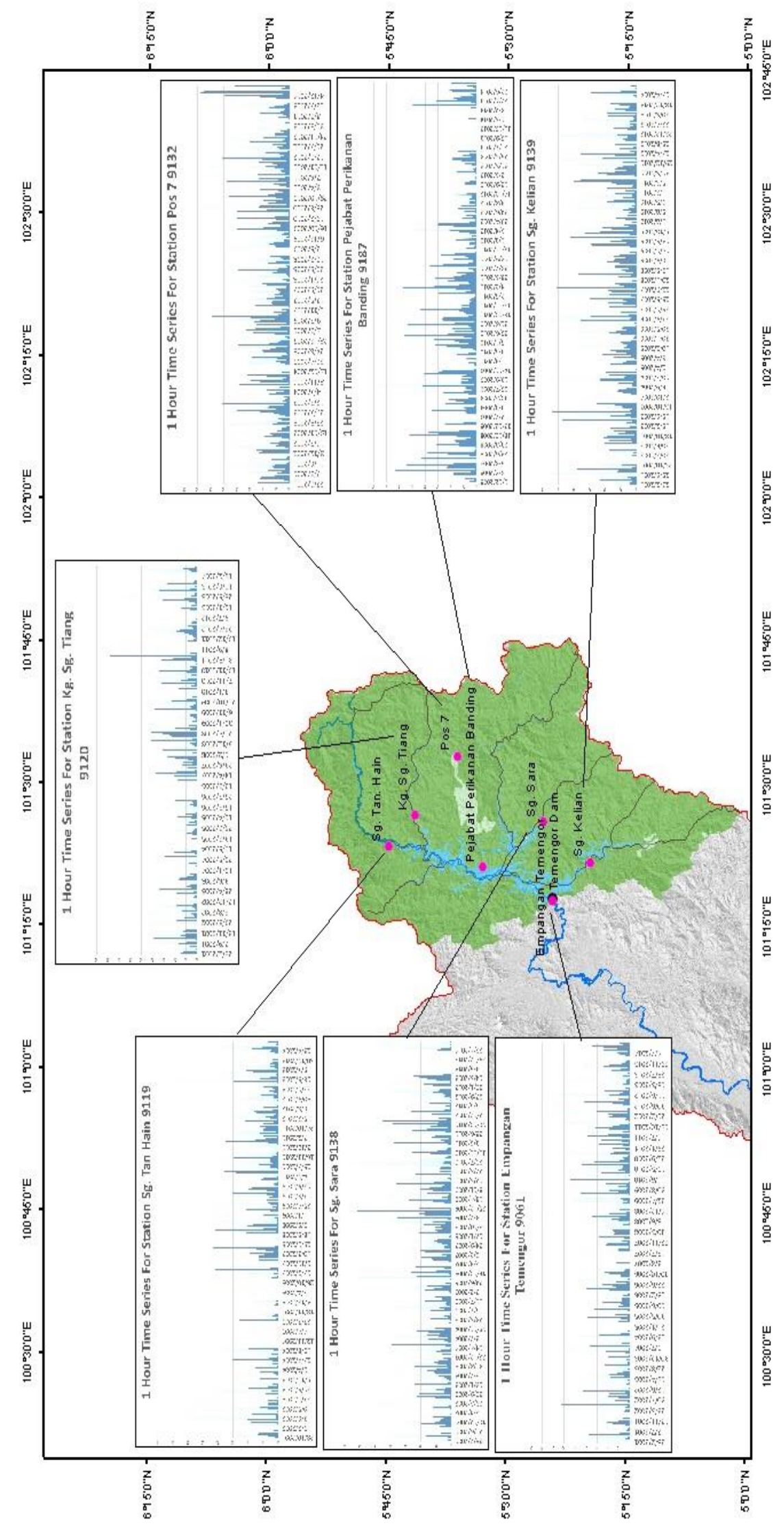

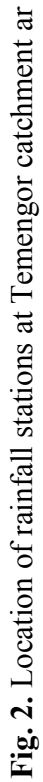

